5

7

8

9

10

11

\title{
Effects of Fog, Driver Experience and Gender on Driving Behavior
} on S-Curved Road Segments

\author{
Xiaomeng $\mathrm{Li}^{1}$, Xuedong Yan $^{2 *}$, S.C. Wong ${ }^{3}$
}

1. Xiaomeng Li, MOE Key Laboratory for Urban Transportation Complex System Theory and Technology, School of Traffic and Transportation, Beijing Jiaotong University, Beijing 100044, China. Tel: 138-1029-3423, E-mail: 13114249@bjtu.edu.cn.

2. Xuedong Yan, Ph.D. (Corresponding Author), Professor, MOE Key Laboratory for Urban Transportation Complex System Theory and Technology, School of Traffic and Transportation, Beijing Jiaotong University, Beijing 100044, China. Tel: 158-1007-4718, E-mail: xdyan@bjtu.edu.cn.

3. S.C. Wong, Ph.D., Department of Civil Engineering, The University of Hong Kong, Pokfulam Road, Hong Kong, China. Tel: (852) 2559-5337, E-mail: hhecwsc@hku.hk. 


\section{Abstract}

Driving on curved roads has been recognized as a significant safety issue for many years. However, driver behavior and the interactions among variables that affect driver performance on curves is complicated and not well understood. Previous studies have investigated various factors that influence driver performance on rightor left-turn curves, but have paid little attention to the effects of foggy weather, driver experience and gender on driver performance on complex curves. A driving simulator experiment was conducted in this study to evaluate the relationships between driving behavior on a continuous S-curve and foggy weather, driver experience and gender. The process of negotiating a curve was divided into three stages consisting of a straight segment, the transition from the straight segment to the S-curve and the S-curve. The experimental results indicated that drivers tended to drive more cautiously in heavy fog, but the driving risk was still increased, especially in the transition stage from the straight segment to the S-curve. The non-professional (NP) drivers were less sensitive to the impending change in the road geometry, and less skilled in both longitudinal and lateral vehicle control than the professional drivers. The NP female drivers in particular were found to be the most vulnerable group in S-curve driving.

Keywords: Driving simulator; S-curve; Driving behavior; Fog weather; Driver experience; Driver gender 


\section{Introduction}

As a special component of road design, curves have a comparatively complex road geometry that makes driving more difficult (Hummer et al., 2010). Typically, a road that violates a driver's expectations is more hazardous than a road that does not. Thus, complex curves (generally with small radius and short tangent) are always accident prone locations. According to traffic accident data from China, about $7.84 \%$ of the road traffic accidents occur on curved roads (Gao and Wang, 2005). Apart from the crash rate, the high severity of crashes on curves is also worthy of attention. In the United States, about 5000 fatalities a year result from single-vehicle run-off-road crashes on the curved sections of two-lane rural roads (National Highway Traffic Safety Administration, 2011). A large proportion of these accidents are caused by drivers travelling too fast through a curve, and either losing control of the vehicle or being forced into a corner-cutting maneuver to maintain control of the vehicle, thus increasing the likelihood of a collision with an oncoming vehicle (Comte and Jamson, 2000). The particular road alignment of curves also reduces sight distance, limiting drivers' anticipation of the road ahead and upcoming traffic situations and leading to higher uncertainty about the course of the road (Martens et al., 1997). Overall, a high number of traffic accidents are closely associated with drivers' inappropriate driving maneuvers induced by the particular road geometry.

Negotiating a road curve requires that drivers adjust their speed and lane position to accommodate the severity of the curve (Reymond et al., 2001), which requires greater 
control of the pedals and steering to maneuver the vehicle safely. Coutton-Jean et al. (2009) argued that driving through curves requires a fast and reliable analysis of the spatial-temporal parameters necessary to keep the vehicle on the road. Similarly, Charlton (2007) indicated that the curve driving task is complex as drivers need to allocate more attentional resources to collecting information and more mental resources to making decisions, and thus have less time for manual control. To perform well on curves, drivers must properly perceive traffic objects (e.g., road signs), keep alert to make decisions and perform driving actions at the right time (Roca et al., 2012). However, some researchers have reported that drivers tend to misperceive upcoming curves (Shinar, 1977; Chang, et al., 2008) or underestimate their vehicle speed on curves (Maltz and Shinar, 2007; Johnston, 1982). Others have found that the potential for erroneous perception increases with the complexity of the road alignment (Bidulka et al., 2002; Smith and Lamm, 1994).

Although driving on curves has long been an important global traffic safety problem, there has been little consensus on identifying the proximal causes of crashes on curves. However, it is undeniable that nearly all such crashes are associated with inappropriate driving behavior. Driving performance has become a focus of concern in the area of curve safety research.

\subsection{Factors associated with curve safety}

Previous studies have identified numerous factors that influence driving performance and safety on curves. These factors can be divided into four main types: road 
101

102

103

characteristic, environmental conditions, vehicle-related factors and driver-related factors. The studies related to road characteristics include the curve radius/curvature (Coutton-Jean et al., 2009; Bella et al., 2014; Boer, 1996), edge lines (Coutton-Jean et al., 2009), lane width (Robertshaw and Wilkie, 2008; Coutton-Jean et al., 2009), curve length (Zuriaga et al., 2010; Hu and Donnell, 2010) and pavement condition (Buddhavarapu et al., 2013; Zador et al., 1987). The research related to environmental conditions in curve segments includes weather conditions (Jung et al., 2014; Yan et al., 2014), nighttime (Bella et al., 2014; Hu and Donnell, 2010), roadside clearance (Aram, 2010; Bella, 2013), sight distance (Kondo and Ajimine, 1968), traffic volume (Aram, 2010; AASHTO, 2010) and markings and speed signs (Rutley, 1972; Comte and Jamson, 2000). The vehicle-related factors can significantly influence the relevant driving behaviors and running out of curve crashes, such as vehicle type (Liu and Subramanian, 2009; Fitzsimmons et al., 2013) and vehicle occupancy (Liu and Ye, 2011). The typical driver-related factors associated with driving performances in curve segments include alcohol or drug use (Buddhavarapu et al., 2013), age (Tsimhoni and Green, 1999), driving style (de Groot, et al., 2012; Evans, 2006) and driving experience (Cavallo et al., 1988).

Furthermore, motorists are sometimes expected to reduce their operating speed to $30 \sim 40 \mathrm{~km} / \mathrm{h}$ from $80 \sim 100 \mathrm{~km} / \mathrm{h}$ quickly when the road condition changes, especially when straight highway segment connected with sharp curve segments (Xu, 2011). The problem in speed reduction in high-to-low speed transitions area, which is often called 
transition zones, is a hotspot and thorny issue worldwide in recent years (Cruzado and Donnell, 2010; Dixon et al., 2008; Debnath et al., 2014). According to the China Guidelines for Safety Audit of Highway (JTG/T B05-2004), when the difference in operating speeds between two adjacent road segment is larger than $20 \mathrm{~km} / \mathrm{h}$, the consistency of operating speed will be affected, thus it is recommended to insert a transition zone between the two segments or set warning signs in advance before the low speed limit segment. Nevertheless, there is still a lack of national guidance for providing practitioners clear design standards on speed transition zone in China.

\subsection{Influence of fog on driving behavior and safety on curves}

According to cognitive theories, driving performance is determined by the driver's decision-making system, which is based on acquired information (Salvucci, 2004; Ng and Chan, 2008). Most of the information required by the driver is perceived visually. Fog, as a type of inclement weather, has an enormous negative influence on drivers' visibility, which causes quite a change in driving behavior. Previous studies of driving behavior in fog have focused on drivers' car following performance (Broughton et al., 2007; Kang et al., 2008; Ni et al., 2010), collision avoidance performance (Ni et al., 2012; Mueller and Trick, 2012) and behavior/responses to road sign instructions (Hassan and Abdel-Aty, 2011; Trick et al., 2010). However, little research has investigated how drivers perform on roads with complex alignments such as S-curves when driving in fog. Shinar et al. (1977) and Tsimhoni and Green (1999) explored a back-and-forth visual pattern showing that drivers need more visual information on a curved road. However, under foggy conditions, the reduction in contrast of the 
surrounding scene can obscure important visual information that is fundamental for driving on a curve. Thus, as a potential risk factor for driving safety on curves, the effect of foggy weather should be emphasized.

\subsection{Influence of driver experience and gender on driving behavior}

In recent years, researchers have paid increasing attention to the human factors related to driving (Lajunen, 1997), including driver experience and gender. In the present study, driver experience was measured by whether the driver was a professional driver (mainly taxi drivers) or a casual driver, so the drivers were divided into two groups: professional drivers and non-professional (NP) drivers. The former are regarded as an unique group and have become a popular target for research (Burns and Wilde, 1995; Botes, 1997; Peltzer and Renner, 2003). However, most studies have focused on professional drivers' crash-related characteristics or risk-taking behavior (Rosenbloom and Shahar, 2007; La et al., 2013; Burns and Wilde, 1995). In fact, professional drivers' extensive driving time and mileage trains them to develop better skills and experience of vehicle control. Professional drivers have been found to have better performance on complex road segments than NP drivers (Yan et al., 2014). The demands of their work also facilitate professional drivers to drive more cautiously. It was reported that taxi, minibus and heavy vehicle drivers drive slower than NP drivers on highways (Öz et al., 2010). Compared with professional drivers, NP drivers are comparatively less experienced and lack driving skills. Inexperienced drivers tend to have an elevated mental workload and inefficient visual search, hazard perception and vehicle control abilities (Crundall, et al., 1999; Falkmer and Gregersen, 2005). Among 
171 inexperienced drivers, accidents on curves are mostly due to loss of control involving 172 excessive speed (Clarke et al., 2006; Laapotti and Keskinen, 1998) and poor trajectory 173 planning skills (Lehtonen, et al., 2014).

Gender is one of the most often measured variables in driving behavior studies, and has been identified as a key demographic variable influencing driving violations and

177 collision risk. It has long been believed that men are more likely to be involved in motor-vehicle crashes (Blockey and Hartley, 1995; Doherty et al., 1998) and are more prone to take risks than female drivers (Deery, 1999). However, recent research from a variety of countries (e.g., Australia, New Zealand, Finland, and the UK) indicates that women are closing the gap (Attewell, 1998; Laapotti et al., 2001). Female drivers are now over-represented in crashes compared to males, caused by errors in yielding, gap acceptance and speed regulations (Classen et al., 2012). Studies in Europe have found that although females have a greater safety orientation than males, young female drivers have more problems in vehicle handling and mastering traffic situations (Laapotti et al., 2001, 2003). Thus, it is reasonable to suggest that the difference in physiological features and psychological mechanisms between male and female drivers may result in different curved road driving characteristics.

\subsection{Objectives of this study}

Although numerous studies have focused on curve driving and several factors have been confirmed to be associated with driving safety on curves, the effects of foggy weather, drivers' experience and gender have been neglected. Furthermore, China is a 
country with large proportion of mountainous terrain (over 30\%). Especially for some provinces such as Fujian, Yunnan and Sichuan, etc., it is common for complex-alignment roads (continuous sharp curves for example) built in the mountain areas. However, most of the previous simulation-based curve-driving studies were conducted on right- or left-turn curves (Coutton-Jean et al. 2009; Comte and Jamson, 2000; Charlton, 2004), but paid little attention to drivers' maneuvering process on complex curves such as continuous S-curves. Thus, this study evaluated the effects of foggy weather, driver experience and gender on drivers' maneuvering process while approaching and navigating an S-curve, including their average speed, deceleration distance, maximum deceleration before the curve, longitudinal and lateral vehicle control stability, etc.

\section{Method}

\subsection{Subjects}

The experiment was a 3 (fog) $\times 2$ (gender) $\times 2$ (experience) within-subjects repeated measures design. Forty-six participants were recruited. The participants had no long-term or short-term health problems according to their self reports and did not suffer from motion sickness during a five minutes test drive and formal experiment in the simulator. Each participant held a valid Beijing’s driver license and had at least one year driving experience. The participants were allocated to two groups according to their profession: 21 professional taxi drivers (13 males, 8 females) and 25 non-professional casual drivers (13 males, 12 females). The professional drivers were full-time taxi drivers with an average annual driving distance of 74.3 thousand 
kilometers and an average self-reported accident rate of 7 per million kilometers. The non-professional drivers used their vehicles for the purpose of daily travel only. Their average mileage was 13.3 thousand kilometers per year, with an average self-reported accident rate of 15 per million kilometers. The participants ranged from 20 to 52 years of age (S.D. = 9.7), with an average of 33.5.

\subsection{Apparatus}

The Beijing Jiaotong University (BJTU) driving simulator was used to conduct the experiment and collect the data, as shown in Figure 1. The BJTU simulator is a high-performance, high-fidelity driving simulator with a linear motion base capable of operating with 1 degree of freedom. It is composed of a full-size vehicle cabin (Ford Focus) with a real operational interface, environmental noise and shaking simulation system, digital video replay system and vehicle dynamic simulation system. The simulated environment is projected with a front/peripheral field of view of 300 degrees at a resolution of $1400 \times 1050$ pixels and left, middle and right rear-view mirrors. The simulator lab is provided with software for driving scenario design, virtual traffic environment simulation and virtual road modeling.

\subsection{Scenario design and data collection}

The $3 \times 2 \times 2$ within-subjects design presented three fog levels: no fog, light fog and heavy fog, as shown in Figure 2. The visibility in the light and heavy fog scenarios was $250 \mathrm{~m}$ and $50 \mathrm{~m}$, respectively. The experimental road for the driving simulation was composed of straight segments and an S-curve segment, both of which were 
two-way with two lanes $3.5 \mathrm{~m}$ wide. The S-curve segment was $200 \mathrm{~m}$ long, connected with a $400 \mathrm{~m}$ entry straight segment, and this test track is part of the road network in the study of Yan et al. (2014). Detailed dimensions of the experimental road were shown in Figure 3. Considering that the smallest radius of the S-curve was less than $30 \mathrm{~m}$, the speed limit of the curved segment was set at $30 \mathrm{~km} / \mathrm{h}$ according to the Design Specification for Highway Alignment of China (JTG D20-2006), and the speed limit on the straight segment was $80 \mathrm{~km} / \mathrm{h}$. Oncoming traffic was present on the straight sections, but there was no other traffic in either the driver's lane or in the oncoming lane on the curve. Each participant drove along the test route three times, under no fog, light fog and heavy fog conditions. To counterbalance the effects of time order, the weather conditions were arranged in a random sequence.

The National Cooperative Highway Research Program (NCHRP) Report 600B, Human Factor Guidelines for Roadway Systems, defines the key steps in horizontal curve negotiation (Campbell et al., 2008), from curve discovery to exit. To drive through the curve safely, the important tasks for the driver include identifying the change in alignment, determining the difficulty level of the curve (e.g. curvature) at the transition, then adjusting speed and maintaining the proper lane position through the curve (Fitzsimmons et al., 2013). In the present study, the process of negotiating the S-curve was divided into three stages: (1) the straight segment driving stage, (2) the transition stage from the straight segment to the S-curve and (3) the within-curve stage, as shown in Figure 3. The experimental results and discussion sections are presented according to these stages. 
269 During the experiment, the simulator data were sampled at $10 \mathrm{~Hz}$. Key variables were extracted from the original simulator data for the analyses. The dependent variables

271 were the average speed, deceleration distance, maximum deceleration, number of 272 departures (number of times the simulator crossed the lane boundaries), maximum 273 lane position (maximum distance between the center of the simulator and the center of 274 the lane), speed S.D. (standard deviation of the driver's speed) and lane position S.D. 275 (standard deviation of the driver's lane position). The dependent variables were analyzed using repeated-measures (within-subjects) ANOVA. As an extension of the

277 paired t-test, repeated-measures ANOVA is often used to determine whether changes have occurred over time, thus it compares the average score at multiple time points

279 for a single group of subjects. In this study, fog condition was a within-subjects factor, 280 and driver gender and experience were between-subjects factors. The hypothesis 281 testing in the following analyses was based on a significance level of 0.05.

282

283

\subsection{Experimental procedure}

Upon arrival, participants were briefed on the requirements of the experiment and were asked to read and sign an informed consent form. They were then advised to drive and behave as they normally would and to adhere to traffic laws as in real-life situations. The participants were also notified that they could quit the experiment at any time in case of motion sickness or any kind of discomfort. Before the formal experiment, the participants were given at least 10 minutes of training to familiarize them with the driving simulator operation. Next, they performed the formal 
experiments under the three weather conditions (clear, light fog and heavy fog) in a random sequence to eliminate any order effects, and a break of at least 5 minutes was allowed between the three tests.

\section{Experimental Results}

\subsection{Straight segment driving stage}

In this stage, participants drove the straight segment and had no perception of the S-curve. Thus, their driving behavior was not affected by the road alignment change. Table 1 shows the descriptive statistics for the average speed during this stage and the ANOVA results for the differences between factors. Both the fog condition ( $F=59.10$, $\mathrm{p}<0.01)$ and driver experience $(\mathrm{F}=6.61, \mathrm{p}<0.05)$ significantly influenced the average speed, while there were no gender effect or interaction effects among the factors. The average speed was lowest in heavy fog $(M=48.72 \mathrm{~km} / \mathrm{h}$, S.D. $=9.43 \mathrm{~km} / \mathrm{h})$, and there was no obvious difference between the average driving speeds in no fog ( $M=63.20$ km/h, S.D.=10.37 km/h) and light fog (M=64.03 km/h, S.D.=11.03 km/h) (see Figure 4a). The professional drivers drove slower $(M=55.38 \mathrm{~km} / \mathrm{h}$, S.D. $=12.32 \mathrm{~km} / \mathrm{h})$ than the NP drivers (M=61.39 km/h, S.D.=11.90 km/h) (see Figure 4b).

\subsection{Transition stage from straight segment to S-curve}

The transition stage is located at the entry to the curve. Typically, drivers identify the change in road alignment and make an initial deceleration action at this stage. In general, the safe negotiation of a curve depends, in part, on the driver perceiving the change in alignment and selecting appropriate operating maneuvers. However, the 
perception of a curve and the maneuvers selected can be distorted by external factors such as fog, or internal factors such as driver experience and gender. Thus, the effects of fog, driver experience and gender on the key variables-deceleration distance, maximum deceleration, average speed and number of departures—-were examined in this stage.

(1) Deceleration distance

Deceleration distance was measured as the distance between the point where the driver began to decelerate and the first turning point of the S-curve. In this experiment, three participants did not perform any braking action before the S-curve in the heavy fog condition. The mean deceleration distances and the ANOVA results for the differences between factors are listed in Table 2. Both fog $(\mathrm{F}=17.55, \mathrm{p}<0.01)$ and driver experience $(\mathrm{F}=4.10, \mathrm{p}<0.05)$ significantly influenced deceleration distance, while no significant gender effect or interaction effects were observed. Among the three fog conditions, the mean deceleration distance was significantly shorter in heavy fog $(M=59.72 \mathrm{~m}$, S.D. $=38.04 \mathrm{~m})$ than in no fog $(\mathrm{M}=95.42 \mathrm{~m}$, S.D. $=40.09 \mathrm{~m})$ and light fog $(M=98.77 \mathrm{~m}$, S.D.=38.11 m) (see Figure 5a). The professional drivers' deceleration distance $(\mathrm{M}=91.86 \mathrm{~m}$, S.D. $=43.25 \mathrm{~m})$ was longer than that of the NP drivers (M=79.53 m, S.D. $=40.90 \mathrm{~m})$ (see Figure 5b).

(2) Maximum deceleration rate

The maximum deceleration rate was measured as the maximum absolute value of deceleration that drivers adopted after perceiving the curve in the transition stage from 
341

the straight segment to the S-curve. The descriptive statistics for the maximum deceleration rate and the ANOVA results of the differences between factors are shown in Tables 3. Only fog significantly influenced the drivers’ maximum deceleration rate in the transition stage $(\mathrm{F}=4.02, \mathrm{p}<0.05)$, with no significant experience or gender effects or interaction effects among the factors. The maximum deceleration rate was lowest in heavy fog $\left(M=2.68 \mathrm{~m} / \mathrm{s}^{\wedge} 2\right.$, S.D.=1.06 m/s^2), followed by no fog $(\mathrm{M}=3.35$ $\mathrm{m} / \mathrm{s}^{\wedge} 2$, S.D. $\left.=1.12 \mathrm{~m} / \mathrm{s}^{\wedge} 2\right)$ and light fog $\left(\mathrm{M}=3.43 \mathrm{~m} / \mathrm{s}^{\wedge} 2\right.$, S.D. $\left.=1.41 \mathrm{~m} / \mathrm{s}^{\wedge} 2\right)$, as shown in Figure 6.

\section{(3) Average speed}

The average speeds were calculated for each $10 \mathrm{~m}$ section of the transition stage from the straight segment to the S-curve. Figure 7 shows the speed profiles on the approach to the curve in different fog conditions. At the beginning of this stage, drivers' speeds continued the trend shown in the straight segment, with the slowest speeds in heavy fog and no obvious difference between speeds in no fog and light fog. Drivers reduced their speeds earlier in no fog and light fog than in heavy fog, which is consistent with the deceleration distance result in the three fog conditions. In addition, there was a delay in the speed reduction before the curve in heavy fog, as drivers did not reduce their speed at a constant rate and the deceleration rate increased as they approached the curve. Even so, the curve entry speed was still higher in heavy fog than in light fog and no fog. In contrast, a smoother rate of deceleration was observed when approaching the curve in light fog and no fog. 
364

365

(4) Number of departures

The number of departures indicates the number of times the simulator crossed the lane boundaries. Excessive lane departure increases the likelihood of run-off-road crashes or head-on collisions with oncoming vehicles. Typically, curve departures are the consequence of improper lane-keeping or loss of vehicle control when the curve is approached too fast. In this experiment, the departures that occurred in the transition stage from the straight segment to the S-curve were mainly concentrated at the end of the stage, i.e., the entry position of the curve. According to the experimental results, 61 departures were recorded. Chi-square tests (see Table 4) showed a significant correlation between fog conditions and the number of departures. The number of departures in no fog, light fog and heavy fog conditions was 19, 14 and 28, respectively.

\subsection{Within-curve stage}

This stage investigated drivers' speed control and lane-keeping behavior within the curve. This was assumed to be the most difficult stage as the drivers had to continually adjust their speed and lane position to keep the simulator trajectory consistent with the curve geometry. To pass through the curve safely, the simulator must remain stable in both longitudinal and lateral directions. Thus, the effects of fog, driver experience, and gender on drivers' speed, speed S.D., maximum lane position and lane position S.D. were examined.

(1) Speed within the curve 
Table 5 lists the average speeds in each $10 \mathrm{~m}$ interval within the $130 \mathrm{~m}$ length of curve (130m is the lateral projective distance) in three fog conditions, and Figure 8 shows the drivers' speed changes within the S-curve under the three fog conditions more visually. The figure shows that the drivers did not maintain a constant speed through the curve as they had to keep adjusting their speed according to the curve geometry. The average speed was slightly higher in the comparatively straight section than at the corner of the curve in all three fog conditions. It is also obvious from the figure that drivers entered the curve at higher speeds in heavy fog than in no fog and light fog, which is consistent with the result in Figure 7.

\section{(2) Speed standard deviation}

The speed S.D. reflects the stability of vehicle speed control when driving within the curve, and is a good indicator of the degree to which drivers were able to keep speed fluctuations under control. Table 6 shows the descriptive statistics for the speed S.D. within the curve and the ANOVA results for the differences between factors. The ANOVA showed significant main effects of gender $(F=7.76, p<0.01)$ and experience $(\mathrm{F}=5.93, \mathrm{p}<0.05)$ on speed S.D. The female drivers' speed S.D. $(\mathrm{M}=3.49$, S.D.=2.40) was significantly larger than that of the male drivers $(M=2.37$, S.D. $=0.93)$ and the NP drivers' speed S.D. $(M=3.23$, S.D.=2.22) was significantly larger than that of the professional drivers $(M=2.41$, S.D.=0.99). The ANOVA also revealed significant interactions between fog and experience $(\mathrm{F}=3.12, \mathrm{p}<0.05)$ and gender and experience $(\mathrm{F}=5.66, \mathrm{p}<0.05)$. As shown in Figure 9a, there was no obvious difference between the speed S.D. of professional drivers and NP drivers in no fog, but the NP drivers' 
speed S.D. was significantly higher than that of the professional drivers in light and heavy fog. Figure 9b shows no obvious difference between the speed S.D. of the professional drivers (both male and female) and the NP male drivers, but the speed S.D. of the NP female drivers was significantly higher than those of the other groups.

(3) Maximum lane position within the curve

The maximum lane position within the curve refers to the maximum distance between the center of the simulator and the center of the lane while driving within the curve. It provides an indication of the driving risk on curve because the possibility of a run-off-road crash or collision with an oncoming vehicle increases as the maximum lane position increases. Table 7 shows the descriptive statistics for the maximum lane position and the ANOVA results for the differences between factors. Only drivers' experience $(\mathrm{F}=8.09, \mathrm{p}<0.05)$ significantly influenced the maximum lane position within the curve, while no significant main effects of fog condition or gender, or interaction effects among the factors were observed. Figure 10 shows that the maximum lane position was larger for NP drivers $(M=1.50 \mathrm{~m}$, S.D. $=0.62 \mathrm{~m})$ than for professional drivers $(\mathrm{M}=1.16 \mathrm{~m}$, S.D. $=0.29 \mathrm{~m})$. In addition, according to the experimental data, the frequency of drivers' maximum lane positions that resulted in their crossing the lane boundaries (both left and right sides) at different locations within curve was counted, as is shown in Figure 11. It can be seen from the figure that the sharp curvature locations within curve are generally run-off road collision prone areas. 
(4) Lane position standard deviation

The lane position S.D. indicates the quality of route tracking and stability within the driving lane. A large lane position S.D. indicates poor route tracking, and signifies that drivers are drifting inside their lanes. Tables 8 show the descriptive statistics for lane position S.D. and the ANOVA results for the differences between factors. Fog condition $(\mathrm{F}=6.77, \mathrm{p}<0.01)$, driver experience $(\mathrm{F}=4.25, \mathrm{p}<0.05)$ and the interaction between gender and experience $(F=4.27, p<0.05)$ had significant effects on the lane position S.D. Furthermore, as the fog density increased, drivers' lane position S.D. decreased, as shown in Figure 12a. Meanwhile, similar to the interaction effect of gender and experience on speed S.D. within the curve, the professional drivers (both male and female) and NP male drivers showed small differences in lane position S.D. within the curve, while the NP female drivers had the largest lane position S.D. (see Figure 12b).

\section{Discussions}

\subsection{Effect of fog conditions}

Driving through a curve in foggy weather is a complex task that requires the driver to consider the interactions between a vehicle and its environment. The presence of fog can reduce not only the visibility but also the visual field. Previous studies have confirmed that drivers tend to perform safety-related adaptations, such as reducing speed, to compensate for the insecurity arising from the limited visual field (Ni et al., 2010; Broughton, 2007). In this study, drivers reduced their speed significantly in the heavy fog condition on the straight road segment. However, it is worth noting that 
there was no speed reduction in the light fog condition compared with the no fog condition. Previous studies have also reported that drivers were only inclined to slow down significantly when the sight distance was drastically reduced by fog (Klinjnhout, 1991; Brooks et al., 2011). The limited visibility induced by fog conditions also resulted in a stable lateral offset of the simulator, as the lane position S.D. decreased as the fog density increased in the curved stage.

Although the drivers tended to perform more cautiously in heavy fog, it was still not sufficient to compensate for the hazards imposed by the inclement weather. Heavy fog increases the driving risk, particularly in the transition stage from the straight segment to the S-curve, where the highest demand on the driver needed to control the vehicle within a curve begins (Campbell et al., 2008), and this can be illustrated in the following two examples.

First, the drivers entered the S-curve at a higher entry speed in heavy fog than those in no fog and light fog conditions (see Figure 7). Although the drivers could perceive the potential risk induced by fog and reduced their speeds for compensation while driving at straight segment in heavy fog, it was difficult for them to respond to the impending changes in road alignment in advance and decelerate in time due to the limited sight distance. As shown in Figure 5 and Figure 7, the drivers began to decelerate closer to the curve in the heavy fog than in the no fog and light fog conditions. In spite of the increased deceleration rate as the drivers approached the curve, the entry speed was 
481

482

still higher in the heavy fog than in the no fog and light fog conditions (see Figure 8), which indicated that the maximum deceleration rate in heavy fog was not large enough before the drivers entered the curve. Thus, the delay in decelerating combined with the lowest maximum deceleration rate in heavy fog led to a higher curve entry speed, representing a higher risk for drivers in negotiating the curve. Field test data have confirmed that a driver's initial speed before entering a curve has a significant effect on the ability to successfully negotiate the curve (Preston and Schoenecker, 1999). Retting and Farmer (1998) found that drivers' perceptions of speed were an obvious contributor to crashes occurring at curves, particularly their speed when approaching and entering a curve. Bella et al. (2014) also indicated that tangent-curve transitions represent the most critical situations, where drivers require correct and timely information to ensure they approach the curve at a suitable speed. If such information is not available or is misleading, it can cause a sudden speed reduction in the transition between two successive elements of road alignment. Obviously, in this experiment, the limited visibility induced by fog impeded the drivers' ability to obtain correct and timely information.

Second, the number of departures was significantly higher in heavy fog than in no fog and light fog (see Table 4). When negotiating a curve during daytime, drivers tend to look at the road ahead more frequently than they look at the road edges (Serafin, 1994). Adequate roadway delineation is needed both to support the driver's immediate need for continuous lane tracking and to provide long-range visual information 
503

504

505

506

507

508

509

510

511

512

513

514

515

(Schieber, 2000). However, visibility is reduced in heavy fog, which obscures the long-range visual information that is important for drivers to predict the path of the road ahead and to anticipate future events. Thus, the absence of long-range information becomes a threat.

\subsection{Driver experience and gender effects}

In the two stages before the curve, the professional drivers performed more cautiously than the NP drivers. The professional drivers drove slower than the NP drivers in the straight segment and they also braked earlier than the NP drivers when approaching the curve in the transition stage from the straight to the S-curve. Similarly, previous research has found that compared with more experienced drivers, less experienced drivers are more likely to speed (Jonah, 1986, 1990), are less sensitive to the potential risk (Yan et al., 2014) and have more speed-related collisions (Curry et al., 2011; Liu et al., 2005).

Furthermore, in the within-curve stage, the NP drivers (especially NP female drivers) were found to be less skilled in maintaining both longitudinal and lateral vehicle control stability, as indicated by the speed S.D. and lane position S.D., respectively. A larger speed S.D. indicates more discrete changes in operating speed, suggesting a potential violation of drivers' expectations that might lead to increased crash risk. The lane position S.D. is often used as an indicator of lateral trajectory control or the amount of "weaving" of the car (Verster and Roth, 2011). The failure to maintain the vehicle in a consistent horizontal position within the driving lane is a primary factor in 
single-vehicle run-off-road accidents and head-on collisions (Verster and Roth, 2011;

Charlton, 2007).

According to the experimental results, the speed of the NP drivers on the curved section was significantly faster than that of the professional drivers in foggy conditions. The NP drivers' maximum lane position was also significantly larger than that of the professional drivers. Similarly, in an experiment comparing inexperienced and experienced drivers on a run of curves, Cavallo et al. (1988) found that only experienced drivers were able to produce the appropriate amount of steering wheel rotation. A simulator experiment conducted by Muttart et al. (2013) showed that experienced drivers had better anticipatory speed regulation when approaching a sharp curve. Thus, it can be inferred that compared with NP drivers, professional drivers have better speed-control and lane-keeping skills due to their extensive driving practice and increased exposure to the diversity of traffic situations.

Much previous research has focused on the relationship between driving risk and gender. Male drivers are deemed to be more likely to engage in risk-taking behavior on the road (Butters et al., 2012; Blockey and Hartley, 1995; Oltedal and Rundmo, 2006). Nevertheless, a survey of driver skills by Özkan and Lajunen (2006) found that male drivers scored higher on perceptual-motor skills than female drivers. In the present study, no main effect of gender was observed for the three stages of curve negotiation, but in the within-curve stage, the NP female drivers had the largest speed 
549

550

551

552

553

554

555

556

557

558

559

560

561

562

563

564

565

566

567

568

569

570

571

572

573

574

575

576

S.D. and lane position S.D., indicating that this is the most vulnerable group when negotiating S-curves.

\section{Conclusions}

This driving simulator experiment demonstrated the effects of fog conditions, driver experience and gender on driving behavior on a complex S-curve. The results indicated that although drivers tended to perform more cautiously in heavy fog, the driving risk was still increased due to the difficulty in perceiving the environment, as indicated by shorter deceleration distances, higher curve entry speeds and more lane departures in heavy fog. In addition, the NP drivers were less skilled in both longitudinal and lateral vehicle control, and the NP female drivers, who had the largest speed S.D. and lane position S.D. within the curve, emerged as a high risk group demanding improvements to reduce risk and ensure safe driving performance. In this study, the oncoming traffic was deemed as an interference factor and was eliminated in experiment design, but it is an important factor in real life that could influence the driving behaviors on curve. Future research would investigate the difference of drivers' performance on curve with no oncoming traffic versus curve with vehicles on the opposite lane.

\section{Acknowledgments}

This research was jointly supported by the Chinese National Natural Science Foundation (71171014 and 71210001), and the University Research Committee of the University of Hong Kong (201309176024). 


\section{References}

AASHTO, 2010. Highway Safety Manual. American Association of State Highway Transportation Officials, Washington, D.C.

Aram, A., 2010. Effective Safety Factors on Horizontal Curves of Two-lane Highways. Journal of Applied Sciences, Vol. 10 (22), pp. 2814-2822.

Attewell, 1998. Women Behind the Wheel: A Statistical Overview of Road Crash Involvement. Federal Office of Road Safety. Canberra, Australia, CR 178.

Bella, F., Calvi, A., D’Amico, F., 2014. Analysis of Driver Speeds under Night Driving Conditions Using a Driving Simulator. Journal of Safety Research, Vol. 49, pp, 45-52.

Bella, F., 2013. Driver Perception of Roadside Configurations on Two-lane Rural Roads: Effects on Speed and Lateral Placement. Accident Analysis and Prevention, Vol. 50, pp. 251-262.

Blockey, P.N., Hartley, L.R., 1995. Aberrant Driving Behaviour: Errors and Violations. Ergonomics, Vol. 38, pp. 1759-1771.

Boer, E., 1996. Tangent Point Oriented Curve Negotiation. In: IEEE Proceedings of the Intelligent Vehicles 1996 Symposium, Tokyo, pp. 7-12.

Bidulka, S., Sayed, T., Hassan, Y., 2002. Influence of Vertical Alignment on Horizontal Curve Perception: Phase I Examining the Hypothesis. Transportation Research Record: Journal of the Transportation Research Board, Vol. 1796, pp. $12-23$.

Botes, G., 1997. A Systemic Study of the Attitudes of Minibus Taxi Drivers towards Traffic Law Enforcement as a Basis for the Formulation of a Management System for the South African Minibus Taxi Industry. Dissertation Abstracts International Section B: The Sciences and Engineering, Vol. 58(3-B). 
603

604

605

606

607

608

609

610

611

612

613

614

615

616

617

618

619

620

621

622

623

624

625

626

627

Broughton, K.L.M., Switzer, F., Scott, D., 2007. Car Following Decisions under Three Visibility Conditions and Two Speeds Tested with a Driving Simulator. Accident Analysis and Prevention, Vol. 39, pp. 106-116.

Brooks, J.O., Crister, M.C., Klein, N, et al., 2011. Speed Choice and Driving Performance in Simulated Foggy Conditions. Accident Analysis and Prevention, Vol. 43(3), pp. 698-705.

Buddhavarapu, P., Banerjee, B., Prozzi, J.A., 2013. Influence of Pavement Condition on Horizontal Curve Safety. Accident Analysis and Prevention, Vol. 52, pp. 9-18.

Burns, P.C., Wilde, G.J.S., 1995. Risk Taking in Male Taxi Drivers: Relationships among Personality, Observational Data and Driver Records. Personality and Individual Differences, Vol. 18, pp. 267-278.

Butters, J., Mann, R.E., Wickens, C.M., Boase, P., 2012. Gender Differences and Demographic Influences in Perceived Concern for Driver Safety and Support for Impaired Driving Countermeasures. Journal of Safety Research, Vol. 43, pp. 405411.

Campbell, J.L., Richard, C.M., Graham, J., 2008. Human Factors Guidelines for Roadway Systems. Washington, DC. NCHRP Report No. 600B.

Cavallo, V., Bran-Dei, M., Laya, O., Neboit, M., 1988. Perception and Anticipation in Negotiating Curves: The Role of Driving Experience. Vision in Vehicles II, Second International Conference on Vision in Vehicles, Nottingham, UK.

Charlton, S.G., 2004. Perceptual and Attentional Effects on Drivers' Speed Selection at Curves. Accident Analysis and Prevention, Vol. 36, pp. 877-884.

Charlton, S.G., 2007. The Role of Attention in Horizontal Curves: A Comparison of Advance Warning, Delineation, and Road Marking Treatments. Accident Analysis and Prevention, Vol. 39 (5), pp. 873-885. 
Chang, S.H., Lin, C.Y., Fung, C.P., Hwang, J.R., D., J.L., 2008. Driving Performance Assessment: Effects of Traffic Accident Location and Alarm Content. Accident Analysis and Prevention, Vol. 40 (5), pp. 1637-1643.

Clarke, D.D., Ward, P., Bartle, C., Truman, W., 2006. Young Driver Accidents in the UK: The Influence of Age, Experience, and Time of Day. Accident Analysis and Prevention, Vol. 38 (5), pp. 871-878.

Classen, S., Wang, Y., Crizzle, A.M., Winter, S.M., Lanford, D.N., 2012. Gender Differences among Older Drivers in a Comprehensive Driving Evaluation. Accident Analysis and Prevention, Vol. 61, pp. 146-152.

Comte, S.L., Jamson, A.H., 2000. Traditional and Innovative Speed-reducing Measures for Curves: An Investigation of Driver Behaviour Using a Driving Simulator. Safety Science, Vol. 36, pp. 137-150

Coutton-Jean, C., Mestre, D.R., Goulon, C., Bootsma, R.J., 2009. The Role of Edge Lines in Curve Driving. Transportation Research Part F, Vol. 12, pp. 483-493.

Crundall, D., Underwood, G., Chapman, P., 1999. Driving Experience and the Functional Field of View. Perception, Vol. 28, pp. 1075-1087.

Cruzado, I. and Donnell, E.T., 2010. Factors Affecting Driver Speed Choice Along Two-lane Rural Highway Transition Zones. Journal of Transportation Engineering, Vol. 136(8), pp. 755-764.

Curry, A.E., Hafetz, J., Kallan, M.J., Winston, F.K., Durbin, D.R., 2011. Prevalence of Teen Driver Errors Leading to Serious Motor Vehicle Crashes. Accident Analysis and Prevention, Vol. 43(4), pp. 1285-1290.

Debnath, A.K., Blackman, R., Haworth, N., 2014. A Tobit Model for Analyzing Speed Limit Compliance in Work Zones. Safety Science, vol. 70, pp. 367-377.

Deery, H.A., 1999. Hazard and Risk Perception among Young Novice Drivers. 
Journal of Safety Research, Vol. 30(4), pp. 225-236.

De Groot, S., Centeno Ricote, F., de Winter, J.C.F., 2012. The Effect of Tire Grip on Learning Driving Skill and Driving Style: A Driving Simulator Study. Transportation Research Part F, Vol. 15, pp. 413-426.

Design Specification for Highway Alignment (JTG D20-2006). Ministry of Transport of the People’s Republic of China, 2006.

Dixon, K., Zhu, H., Ogle, J., et al., 2008. Determining Effective Roadway Design Treatments for Transitioning from Rural Areas to Urban Areas on State Highways. FHWA Report No. FHWA-OR-RD-09-02, Alexandria, USA.

Doherty, S.T., Andrey, J.C., Mac Gregor, C., 1998. The Situational Risks of Young Drivers: The Influence of Passengers, Time of Day and Day of Week on Accident Rates. Accident Analysis and Prevention, Vol. 30(1), pp. 45-52.

Evans, L., 2006. Innate Sex Differences Supported by Untypical Traffic Fatalities. Chance, Vol. 19, pp. 10-15.

Falkmer, T., Gregersen, N.P., 2005. A Comparison of Eye Movement Behavior of Inexperienced and Experienced Drivers in Real Traffic Environments. Optometry and Vision Science, Vol. 82, pp. 732-739.

Gao, J., Wang, W., 2005. Highway Alignment Design. The Yellow River Water Conservancy Press, Zhengzhou, China, pp. 5-6.

Guidelines for Safety Audit of Highway (JTG/T B05-2004). The Ministry of Communications of PRC, 2004.

Hassan, H.M., Abdel-Aty, M.A., 2011. Analysis of Drivers’ Behavior under Reduced Visibility Conditions Using a Structural Equation Modeling Approach. Transportation Research Part F, Vol. 14, pp. 614-625.

Hummer, J.E., Rasdorf, W., Findley, D.J., Zegeer, C.V., Sundstrom, C.A., 2010. Curve 
Crashes: Road and Collision Characteristics and Countermeasures. Journal of Transportation Safety and Security, Vol. 2 (3), pp. 203-220.

Hu, W., Donnell, E.T., 2010. Models of Acceleration and Deceleration Rates on a Complex Two-lane Rural Highway: Results from a Nighttime Driving Experiment. Transportation Research Part F, Vol. 13, pp. 397-408.

Johnston, I.R., 1982. Modifying Driver Behaviour on Rural Road Curves: a Review of Recent Research. In: Proceedings of the 11th Australian Road Research Board (ARRB) Conference, Vol. 11(4), pp. 115-124.

Jonah, B.A., 1986. Accident Risk and Risk-taking Behavior among Young Drivers. Accident Analysis and Prevention, Vol. 18(4), pp. 255-271.

Jonah, B. A., 1990. Age differences in Aggressive Driving. Health and Educational Research, Vol. 5(2), pp. 139-149.

Jung, S., Jang, K., Yoon, Y., Kang, S., 2014. Contributing Factors to Vehicle to Vehicle Crash Frequency and Severity under Rainfall. Journal of Safety Research, Vol. 50, pp. 1-10.

Kang, J.J., Ni, R., Andersen, G.J., 2008. The Effects of Reduced Visibility from Fog on Car Following Performance. Transportation Research Record: Journal of the Transportation Research Board, Vol. 2069, pp. 9-15.

Klinjnhout, J.J., 1991. Fog Crashes Investigation. Ministry of Transport and Public Works, The Netherlands.

Kondo, M., Ajimine, A., 1968. Driver's Sight Point and Dynamics of the Driver-vehicle-system Related to it. SAE Paper No. 680104, Automotive Engineering Congress, Detroit, MI, January 8-12.

La, Q.N., Lee, A.H., Meuleners, L.B., Duong, D.V., 2013. Prevalence and Factors Associated with Road Traffic Crash among Taxi Drivers in Hanoi, Vietnam. 
Accident Analysis and Prevention, Vol. 50, pp. 451-455.

704

705

706

707

708

709

710

711

712

713

714

715

716

Laapotti, S., Keskinen, E., 1998. Differences in Fatal Loss-of-control Accidents between Young Male and Female Drivers. Accident Analysis and Prevention, Vol. 30 (4), pp. 435-442.

Laapotti, S., Keskinen, E., Hatakka, M., Katila, A., 2001. Novice Drivers’ Accidents and Violations—a Failure on Higher or Lower Hierarchical Levels of Driving Behaviour. Accident Analysis and Prevention, Vol. 35 (6), pp. 759-769.

Laapotti, S., Keskinen, E., Rajalin, S., 2003. Comparison of Young Male and Female Drivers’ Attitude and Self-reported Traffic Behaviour in Finland in 1978 and 2001. Journal of Safety Research, Vol. 35 (5), pp. 579-587.

Lajunen, T., 1997. Personality Factors, Driving Style and Traffic Safety. University of Helsinki, Helsinki.

Lehtonen, E., Lappi, O., Koirikivi, L., Summala, H., 2014. Effect of Driving Experience on Anticipatory Look-ahead Fixations in Real Curve Driving. Accident Analysis and Prevention, Vol. 70, pp. 195-208.

Liu, C., Chen, C., Subramanian, R., Utter, D., 2005. Analysis of Speeding-related Fatal Motor Vehicle Traffic Crashes (Technical Report DOT HS 809 839). National High-way Traffic Safety Administration, Washington, DC.

Liu, C., Ye, T.J., 2011. Run-Off-Road Crashes: An On-Scene Perspective, Report No. DOT HS 811 500, National Highway Traffic Safety Administration, Washington DC.

Liu, C., Subramanian, R., 2009. Factors Related to Fatal Single-Vehicle Run-Off-Road Crashes, Report No. DOT HS 811 232, National Highway Traffic Safety Administration, Washington, DC.

Maltz, M., Shinar, D., 2007. Imperfect In-vehicle Collision Avoidance Warning 
Systems can Aid Distracted Drivers. Transportation Research Part F, Vol. 10, pp. 345-357.

Martens, M., Comte, S., Kaptein, N., 1997. The Effects of Road Design on Speed Behaviour: ALiterature Review. Deliverable D1 (Report 2.3.1), MASTER.

Mueller, A.S., Trick, L.M., 2012. Driving in Fog: The Effects of Driving Experience and Visibility on Speed Compensation and Hazard Avoidance. Accident Analysis and Prevention, Vol. 48, pp. 472-479.

Muttart, J.W., Fisher, D.L., Pollatsek, A.P., Marquard, J., 2013. Comparison of Anticipatory Glancing and Risk Mitigation of Novice Drivers and Exemplary Drivers when Approaching Curves. In: Proceedings of the Seventh International Driving Symposium on Human Factors in Driver Assessment, Training, and Vehicle Design.

Neuman, T.R., 1992. Roadway Geometric Design. In: Pline, J.L. (Ed.), Traffic Engineering Handbook, 4th ed. Prentice Hall, Englewood Cliffs, NJ, 154-203.

Ng, Annie W.Y., Chan, Alan H.S., 2008. The Effects of Driver Factors and Sign Design Features on the Comprehensibility of Traffic Signs. Journal of Safety Research, Vol. 39 (3), pp. 321-328.

Ni, R., Bian, Z., Guindon, A., Andersen, G.J., 2012. Aging and the Detection of Imminent Collisions under Simulated Fog Conditions. Accident Analysis and Prevention, Vol. 49, pp. 525-531.

Ni, R., Kang, J.J., Andersen, G.J., 2010. Age-related Declines in Car Following Performance under Simulated Fog Conditions. Accident Analysis and Prevention, Vol. 42, pp. 818-826.

Oltedal, S., Rundmo., T., 2006. The Effects of Personality and Gender on Risky Driving Behaviour and Accident Involvement. Safety Science, Vol. 44, pp. 621- 
628.

754

755

756

757

758

759

760

761

762

763

764

765

766

767

768

769

770

771

772

773

774

775

776

777

Öz, B., Özkan, T., Lajunen, T., 2010. Professional and Non-professional Drivers’ Stress Reactions and Risky Driving. Transportation Research Part F, Vol. 13, pp. 32-40.

ÖzkanT., Lajunen, T., 2006. What Causes the Differences in Driving between Young Men and Women? The Effects of Gender Roles and Sex on Young Drivers’ Driving Behaviour and Self-assessment of Skills. Transportation Research Part F, Vol. 9, pp. 269-277.

Peltzer, K., Renner, W., 2003. Superstition, Risk taking and Risk Perception of Accidents among South African Taxi Drivers. Accident Analysis and Prevention, Vol. 35, pp. 619-623.

Preston, H., Schoenecker, T., 1999. Potential Safety Effects of Dynamic Signing at Rural Horizontal Curves (Report No. MN/RC-2000-14). Minnesota Department of Transportation, St. Paul, Minnesota.

Retting, R.A., Farmer, C.M., 1998. Use of Pavement Markings to Reduce Excessive Traffic Speeds on Hazardous Curves. ITE Journal, Vol. 68 (9), pp. 30-36.

Reymond, G., Kemeny, A., Droulez, J., Berthoz, A., 2001. Role of Lateral Acceleration in Curve Driving: Driver Model and Experiments on a Real Vehicle and a Driving Simulator. Human Factors, Vol. 43 (3), pp. 483-495.

Robertshaw, K. D.,Wilkie, R. M., 2008. Does Gaze Influence Steering around a Bend? Journal of Vision, Vol. 8(4), pp. 1-13.

Roca, Javier, Castro, Cándida, Bueno, Mercedes, Sergio, M.-R., 2012. A Driving Emulation Task to Study the Integration of Goals with Obligatory and Prohibitory Traffic Signs. Applied Ergonomics, Vol. 43(1), pp. 81-88.

Rosenbloom, T., Shahar, A., 2007. Differences between Taxi and Nonprofessional 
Male Drivers in Attitudes towards Traffic-violation Penalties. Transportation Research Part F, Vol. 10, pp. 428-435.

Rutley, K.S., 1972. Advisory Speed Signs for Bends (TRRL Laboratory Report 461). Transport Research Laboratory, Crowthorne, UK.

Salvucci, D.D., 2004. Inferring Driver Intent: A Case Study in Lane Change Detection. In: Proceedings of the Human Factors and Ergonomics Society 48th Annual Meeting 2228-2231, Human Factors and Ergonomics Society, Santa Monica, CA.

Schieber, F., 2000. Highway Research to Enhance the Safety and Mobility of Older Road Users. In: Conference Proceedings 27: Transportation in an Aging Society: A Decade of Experience. Transportation Research Board of the National Academies, Washington, DC, pp. 125-154.

Shinar, D., Mcdowell, E.D., Rockwell, T.H., 1977. Eye Movements in Curve Negotiation. Human Factors: The Journal of the Human Factors and Ergonomics Society, Vol. 19, pp. 63-71.

Shinar, D., 1977. Curve Perception and Accidents on Curves: An Illusive Curve Phenomenon. Applied Ergonomics, Vol. 8(4), pp. 237.

Serafin, C., 1994. Driver Eye Fixations on Rural Roads: Insight Into Safe Driving Behavior (Technical Report No. UMTRI-94-21). The University of Michigan Transportation Research Institute, Ann Arbor.

Smith, B. L., Lamm, R., 1994. Coordination of Horizontal and Vertical Alignment with Regard to Highway Esthetics. Transportation Research Record: Journal of the Transportation Research Board, Vol. 1445, pp. 73-85.

Trick, L.M., Toxopeus, R., Wilson, D., 2010. The Effects of Visibility Conditions, Traffic Density, and Navigational Challenge on Speed Compensation and Driving Performance in Older Adults. Accident Analysis and Prevention, Vol. 42, pp. 
804

805

Tsimhoni, O., Green, P., 1999. Visual Demand of Driving Curves Determined by Visual Occlusion. Presented at the Vision in Vehicles VIII Conference, Boston.

Verster, J. C., Roth, T., 2011. Standard Operation Procedures for Conducting the on-the-road Driving Test, and Measurement of the Standard Deviation of Lateral Position (SDLP). International Journal of General Medicine, Vol. 4, pp. 359-371.

Xu, T., 2011. Speed Zone Division and Speed Transition Zone Setting Research. Beijing University of Technology, pp. 25-26.

Yan, X., Li, X., Liu, Y., Zhao, J., 2014. Effects of Foggy Conditions on Drivers’ Speed Control Behaviors at Different Risk Levels. Safety Science, Vol. 68, pp. 275-287.

Zador, P., Stein, H.S., Wright, P., Hall, J., 1987. Effects of Chevrons, Post-mounted Delineators, and Raised Pavement Markers on Driver Behavior at Roadway Curves. Transportation Research Record, Vol. 1114, pp. 1-10.

Zegeer, C.V., Stewart, R., Reinfurt, D., Council, F.M., Neuman, T., Hamilton, E., Miller, T., Hunter, W., 1990. Cost-effective Geometric Improvements for Safety Upgrading of Horizontal Curves (Publication No. FHWA-RD-90-021). Federal Highway Administration, Washington, DC.

Zuriaga, A.M., Garcia, A., Camacho Torregrosa, F.J., D’ Attoma, P., 2010. Modeling Operating Speed and Deceleration on Two-lane Rural Roads with Global Positioning System Data. Transportation Research Record, Vol. 2171, pp. 11-20. 
826

827

Table 1: Analysis of variance and descriptive statistics for average speed on the straight segment

Table 2: Analysis of variance and descriptive statistics for deceleration distance before the S-curve

Table 3: Analysis of variance and descriptive statistics for maximum deceleration rate before the S-curve

Table 4: Chi-square tests between factors and the number of departures

Table 5: Average speeds within curve

Table 6: Analysis of variance and descriptive statistics for speed S.D. within curve Table 7: Analysis of variance and descriptive statistics for maximum lane position within curve

Table 8: Analysis of variance and descriptive statistics for lane position S.D. within curve

\section{List of Figures}

Figure 1: BJTU driving simulator cab

Figure 2: The three fog conditions

Figure 3: Test road alignment and three stages of the curve negotiation process

Figure 4: Average speed on the straight segment

Figure 5: Deceleration distance in the transition stage from the straight segment to the S-curve

Figure 6: Maximum deceleration rate before the S-curve in three fog conditions Figure 7: Average speed on the approach to the curve in the three fog conditions Figure 8: Speed changes in the three fog conditions 
850 Figure 9: Speed S.D. within the curve

851 Figure 10: Maximum lane position within the curve for different driver experience

852 Figure 11: Frequency of drivers' maximum lane positions resulting in crossing lane

853 boundaries at different locations within curve

854 Figure 12: Lane position S.D. within the curve

855 
Table 1: Analysis of variance and descriptive statistics for average speed on the straight segment

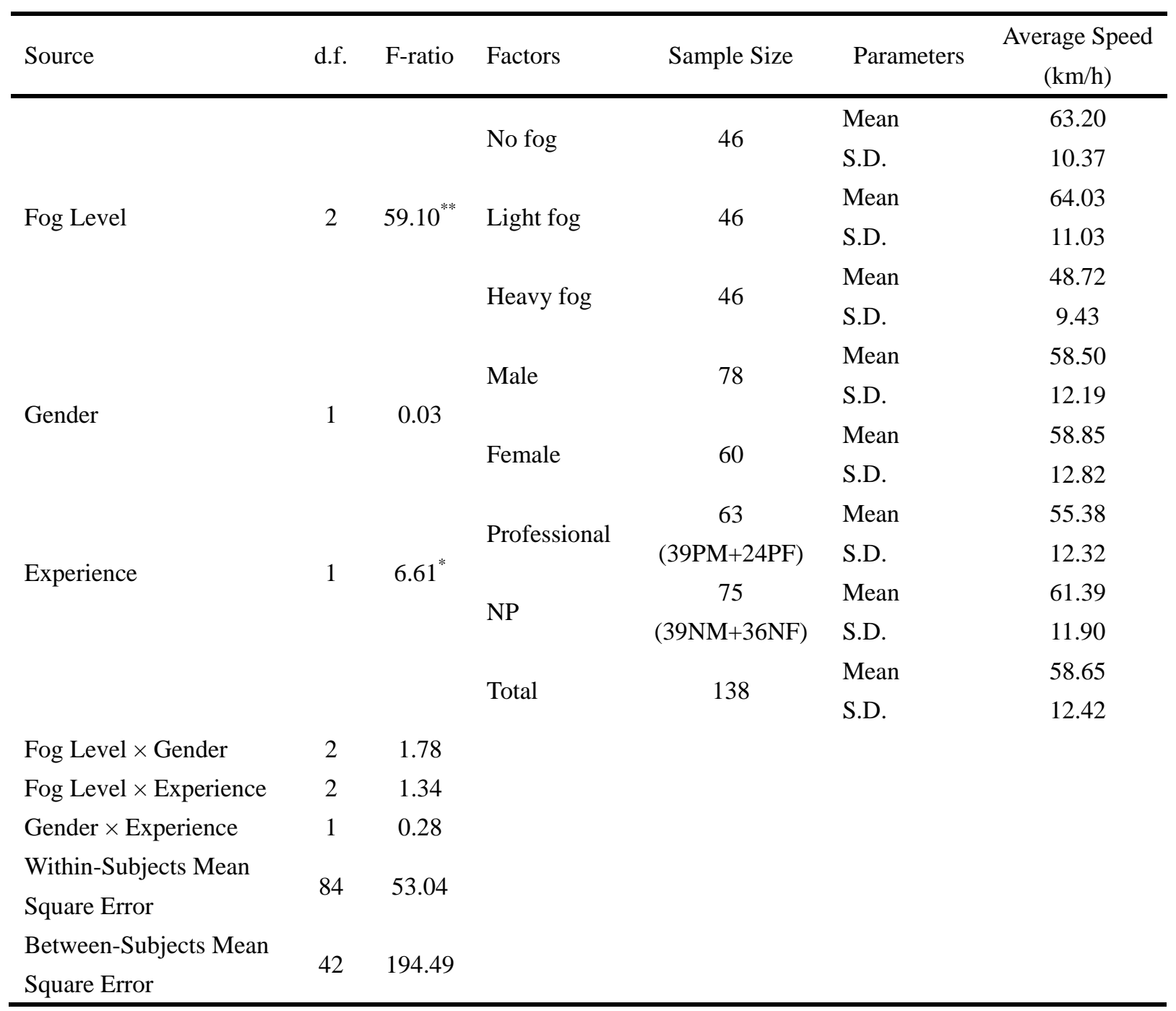

$857{ }^{* *}$ Significant at the 0.01 level. * Significant at the 0.05 level.

858 PM represents professional male drivers. PF represents professional female drivers.

859 NM represents non-professional male drivers. NF represents non-professional female drivers. 
Table 2: Analysis of variance and descriptive statistics for deceleration distance before the S-curve

\begin{tabular}{|c|c|c|c|c|c|c|}
\hline Source & d.f. & F-ratio & Factors & Sample Size & Parameters & $\begin{array}{l}\text { Deceleration } \\
\text { distance (m) }\end{array}$ \\
\hline \multirow{6}{*}{ Fog Level } & \multirow{6}{*}{2} & \multirow{6}{*}{$17.55^{* *}$} & \multirow{2}{*}{ No fog } & \multirow{2}{*}{46} & Mean & 95.42 \\
\hline & & & & & S.D. & 40.09 \\
\hline & & & \multirow{2}{*}{ Light fog } & \multirow{2}{*}{46} & Mean & 98.77 \\
\hline & & & & & S.D. & 38.11 \\
\hline & & & \multirow{2}{*}{ Heavy fog } & \multirow{2}{*}{43} & Mean & 59.72 \\
\hline & & & & & S.D. & 38.04 \\
\hline \multirow{4}{*}{ Gender } & \multirow{4}{*}{1} & \multirow{4}{*}{0.371} & \multirow{2}{*}{ Male } & \multirow{3}{*}{78} & Mean & 83.58 \\
\hline & & & & & S.D. & 42.96 \\
\hline & & & Гomolo & & Mean & 87.39 \\
\hline & & & remale & J/ & S.D. & 41.62 \\
\hline \multirow{6}{*}{ Experience } & \multirow{6}{*}{1} & \multirow{4}{*}{$4.10^{*}$} & \multirow{2}{*}{ Professional } & 62 & Mean & 91.86 \\
\hline & & & & (39PM+23PF) & S.D. & 43.25 \\
\hline & & & \multirow{2}{*}{ NP } & 73 & Mean & 79.53 \\
\hline & & & & $(39 N M+34 N F)$ & S.D. & 40.90 \\
\hline & & & \multirow{2}{*}{ Total } & \multirow{2}{*}{135} & Mean & 85.19 \\
\hline & & & & & S.D. & 42.29 \\
\hline Fog Level × Gender & 2 & 1.03 & & & & \\
\hline Fog Level $\times$ Experience & 2 & 3.01 & & & & \\
\hline Gender $\times$ Experience & 1 & 0.01 & & & & \\
\hline $\begin{array}{l}\text { Within-Subjects Mean } \\
\text { Square Error }\end{array}$ & 78 & 1197.68 & & & & \\
\hline $\begin{array}{l}\text { Between-Subjects Mean } \\
\text { Square Error }\end{array}$ & 39 & 1954.56 & & & & \\
\hline
\end{tabular}


Table 3: Analysis of variance and descriptive statistics for maximum deceleration rate before the

867 S-curve

\begin{tabular}{|c|c|c|c|c|c|c|}
\hline Source & d.f. & F-ratio & Factors & Sample Size & Parameters & $\begin{array}{c}\text { Maximum } \\
\text { Deceleration } \\
\text { Rate }\left(\mathrm{m} / \mathrm{s}^{\wedge} 2\right)\end{array}$ \\
\hline \multirow{6}{*}{ Fog Level } & \multirow{6}{*}{2} & \multirow{6}{*}{$4.02^{*}$} & \multirow{2}{*}{ No fog } & \multirow{2}{*}{46} & Mean & 3.35 \\
\hline & & & & & S.D. & 1.12 \\
\hline & & & \multirow{2}{*}{ Light fog } & \multirow{2}{*}{46} & Mean & 3.43 \\
\hline & & & & & S.D. & 1.41 \\
\hline & & & \multirow{2}{*}{ Heavy fog } & \multirow{2}{*}{43} & Mean & 2.68 \\
\hline & & & & & S.D. & 1.06 \\
\hline \multirow{4}{*}{ Gender } & \multirow{4}{*}{1} & \multirow{4}{*}{0.11} & \multirow{2}{*}{ Male } & \multirow{2}{*}{78} & Mean & 3.19 \\
\hline & & & & & S.D. & 1.29 \\
\hline & & & Eomol & 57 & Mean & 3.13 \\
\hline & & & Гепाале & (I & S.D. & 1.20 \\
\hline \multirow{6}{*}{ Experience } & \multirow{6}{*}{1} & \multirow{4}{*}{0.44} & \multirow{2}{*}{ Professional } & 62 & Mean & 3.22 \\
\hline & & & & (39PM+23PF) & S.D. & 1.24 \\
\hline & & & \multirow{2}{*}{ NP } & 73 & Mean & 3.12 \\
\hline & & & & $(39 N M+34 N F)$ & S.D. & 1.26 \\
\hline & & & \multirow{2}{*}{ Total } & \multirow{2}{*}{135} & Mean & 3.16 \\
\hline & & & & & S.D. & 1.25 \\
\hline Fog Level $\times$ Gender & 2 & 2.94 & & & & \\
\hline Fog Level $\times$ Experience & 2 & 0.36 & & & & \\
\hline Gender $\times$ Experience & 1 & 0.48 & & & & \\
\hline $\begin{array}{l}\text { Within-Subjects Mean } \\
\text { Square Error }\end{array}$ & 78 & 1.33 & & & & \\
\hline $\begin{array}{l}\text { Between-Subjects Mean } \\
\text { Square Error }\end{array}$ & 39 & 1.28 & & & & \\
\hline
\end{tabular}

869 PM represents professional male drivers. PF represents professional female drivers.

870 NM represents non-professional male drivers. NF represents non-professional female drivers. 
Table 4: Chi-square tests between factors and the number of departures

\begin{tabular}{|c|c|c|c|c|c|}
\hline \multirow{2}{*}{ Factors } & \multirow{2}{*}{$\mathrm{N}$} & \multirow{2}{*}{ Ratio $^{\text {b }}$} & \multicolumn{3}{|c|}{ Pearson Chi-Square } \\
\hline & & & Value & d.f. & Asymp. Sig. (2-sided) \\
\hline Fog Level & & & $8.873^{\mathrm{a}}$ & 2 & 0.012 \\
\hline No Fog & 19 & 0.14 & & & \\
\hline Light Fog & 14 & 0.10 & & & \\
\hline Heavy Fog & 28 & 0.20 & & & \\
\hline Gender & & & $0.734^{\mathrm{a}}$ & 1 & 0.391 \\
\hline Male & 32 & 0.23 & & & \\
\hline Female & 29 & 0.21 & & & \\
\hline Experience & & & $0.003^{\mathrm{a}}$ & 1 & 0.958 \\
\hline Professional & 28 & 0.20 & & & \\
\hline NP & 33 & 0.24 & & & \\
\hline
\end{tabular}

$873{ }^{\mathrm{a}}$ Indicates 0 cells $(0.0 \%)$ with expected counts of less than 5.

$874{ }^{\mathrm{b}}$ Indicates the number of departures divided by the number of tests in a certain level of factor. 
878 
Table 6: Analysis of variance and descriptive statistics for speed S.D. within curve

\begin{tabular}{|c|c|c|c|c|c|c|}
\hline Source & d.f. & F-ratio & Factors & Sample Size & Parameters & $\begin{array}{l}\text { Speed S.D. } \\
(\mathrm{km} / \mathrm{h})\end{array}$ \\
\hline \multirow{6}{*}{ Fog Level } & \multirow{6}{*}{2} & \multirow{6}{*}{1.35} & \multirow{2}{*}{ No fog } & \multirow{2}{*}{46} & Mean & 2.60 \\
\hline & & & & & S.D. & 1.03 \\
\hline & & & \multirow{2}{*}{ Light fog } & \multirow{2}{*}{46} & Mean & 2.83 \\
\hline & & & & & S.D. & 2.09 \\
\hline & & & \multirow{2}{*}{ Heavy fog } & \multirow{2}{*}{46} & Mean & 3.14 \\
\hline & & & & & S.D. & 2.09 \\
\hline \multirow{4}{*}{ Gender } & \multirow{4}{*}{1} & & \multirow{2}{*}{ Male } & \multirow{2}{*}{78} & Mean & 2.37 \\
\hline & & $776^{* *}$ & & & S.D. & 0.93 \\
\hline & & & Eomolo & 60 & Mean & 3.49 \\
\hline & & & reminate & 00 & S.D. & 2.40 \\
\hline \multirow{6}{*}{ Experience } & \multirow{6}{*}{1} & \multirow{4}{*}{$5.93^{*}$} & \multirow{3}{*}{ Professional } & 63 & Mean & 2.41 \\
\hline & & & & (39PM+24PF) & S.D. & 0.99 \\
\hline & & & & 75 & Mean & 3.23 \\
\hline & & & NP & (39NM+36NF) & S.D. & 2.22 \\
\hline & & & \multirow{2}{*}{ Total } & \multirow{2}{*}{138} & Mean & 2.86 \\
\hline & & & & & S.D. & 1.81 \\
\hline Fog Level × Gender & 2 & 1.17 & & & & \\
\hline Fog Level × Experience & 2 & $3.12^{*}$ & & & & \\
\hline Gender $\times$ Experience & 1 & $5.66^{*}$ & & & & \\
\hline $\begin{array}{l}\text { Within-Subjects Mean } \\
\text { Square Error }\end{array}$ & 84 & 2.07 & & & & \\
\hline $\begin{array}{l}\text { Between-Subjects Mean } \\
\text { Square Error }\end{array}$ & 42 & 3.89 & & & & \\
\hline
\end{tabular}

${ }^{* *}$ Significant at the 0.01 level. "Significant at the 0.05 level.

881 PM represents professional male drivers. PF represents professional female drivers.

882 NM represents non-professional male drivers. NF represents non-professional female drivers. 
Table 7: Analysis of variance and descriptive statistics for maximum lane position within curve

\begin{tabular}{|c|c|c|c|c|c|c|}
\hline Source & d.f. & F-ratio & Factors & Sample Size & Parameters & $\begin{array}{c}\text { Maximum } \\
\text { Lane } \\
\text { Position (m) }\end{array}$ \\
\hline \multirow{6}{*}{ Fog Level } & \multirow{6}{*}{2} & \multirow{6}{*}{0.54} & \multirow{2}{*}{ No fog } & \multirow{2}{*}{46} & Mean & 1.34 \\
\hline & & & & & S.D. & 0.47 \\
\hline & & & \multirow{2}{*}{ Light fog } & \multirow{2}{*}{46} & Mean & 1.32 \\
\hline & & & & & S.D. & 0.56 \\
\hline & & & \multirow{2}{*}{ Heavy fog } & \multirow{2}{*}{46} & Mean & 1.38 \\
\hline & & & & & S.D. & 0.55 \\
\hline \multirow{4}{*}{ Gender } & \multirow{4}{*}{1} & \multirow{4}{*}{3.74} & \multirow{2}{*}{ Male } & \multirow{2}{*}{78} & Mean & 1.22 \\
\hline & & & & & S.D. & 0.43 \\
\hline & & & Eomalo & 60 & Mean & 1.52 \\
\hline & & & reminale & 00 & S.D. & 0.59 \\
\hline \multirow{6}{*}{ Experience } & \multirow{6}{*}{1} & \multirow{6}{*}{$8.09^{*}$} & \multirow{2}{*}{ Professional } & 63 & Mean & 1.16 \\
\hline & & & & $(39 \mathrm{PM}+24 \mathrm{PF})$ & S.D. & 0.29 \\
\hline & & & \multirow{2}{*}{ NP } & 75 & Mean & 1.50 \\
\hline & & & & (39NM+36NF) & S.D. & 0.62 \\
\hline & & & \multirow{2}{*}{ Total } & \multirow{2}{*}{138} & Mean & 1.35 \\
\hline & & & & & S.D. & 0.52 \\
\hline Fog Level $\times$ Gender & 2 & 1.04 & & & & \\
\hline Fog Level $\times$ Experience & 2 & 1.50 & & & & \\
\hline Gender $\times$ Experience & 1 & 3.29 & & & & \\
\hline $\begin{array}{l}\text { Within-Subjects Mean } \\
\text { Square Error }\end{array}$ & 84 & 0.09 & & & & \\
\hline $\begin{array}{l}\text { Between-Subjects Mean } \\
\text { Square Error }\end{array}$ & 42 & 0.51 & & & & \\
\hline
\end{tabular}

$885{ }^{* *}$ Significant at the 0.01 level. * Significant at the 0.05 level.

886 PM represents professional male drivers. PF represents professional female drivers.

887 NM represents non-professional male drivers. NF represents non-professional female drivers. 
Table 8: Analysis of variance and descriptive statistics for lane position S.D. within curve

Lane

\begin{tabular}{|c|c|c|c|c|c|c|}
\hline Source & d.f. & F-ratio & Factors & Sample Size & Parameters & $\begin{array}{c}\text { Lane } \\
\text { Position } \\
\text { S.D. (m) }\end{array}$ \\
\hline \multirow{6}{*}{ Fog Level } & \multirow{6}{*}{2} & \multirow{6}{*}{$6.77^{* *}$} & \multirow{2}{*}{ No fog } & \multirow{2}{*}{46} & Mean & 0.50 \\
\hline & & & & & S.D. & 0.14 \\
\hline & & & \multirow{2}{*}{ Light fog } & \multirow{2}{*}{46} & Mean & 0.49 \\
\hline & & & & & S.D. & 0.13 \\
\hline & & & \multirow{2}{*}{ Heavy fog } & \multirow{2}{*}{46} & Mean & 0.45 \\
\hline & & & & & S.D. & 0.13 \\
\hline \multirow{4}{*}{ Gender } & \multirow{4}{*}{1} & \multirow{4}{*}{3.24} & \multirow{2}{*}{ Male } & \multirow{3}{*}{78} & Mean & 0.45 \\
\hline & & & & & S.D. & 0.10 \\
\hline & & & \multirow{2}{*}{ Female } & & Mean & 0.52 \\
\hline & & & & 60 & S.D. & 0.16 \\
\hline \multirow{6}{*}{ Experience } & \multirow{6}{*}{1} & \multirow{4}{*}{$4.25^{*}$} & \multirow{2}{*}{ Professional } & 63 & Mean & 0.45 \\
\hline & & & & (39PM+24PF) & S.D. & 0.10 \\
\hline & & & \multirow{2}{*}{ NP } & 75 & Mean & 0.51 \\
\hline & & & & (39NM+36NF) & S.D. & 0.16 \\
\hline & & & \multirow{2}{*}{ Total } & \multirow{2}{*}{138} & Mean & 0.48 \\
\hline & & & & & S.D. & 0.14 \\
\hline Fog Level × Gender & 2 & 1.01 & & & & \\
\hline Fog Level × Experience & 2 & 1.64 & & & & \\
\hline Gender $\times$ Experience & 1 & $4.27^{*}$ & & & & \\
\hline $\begin{array}{l}\text { Within-Subjects Mean } \\
\text { Square Error }\end{array}$ & 84 & 0.01 & & & & \\
\hline $\begin{array}{l}\text { Between-Subjects Mean } \\
\text { Square Error }\end{array}$ & 42 & 0.04 & & & & \\
\hline
\end{tabular}

${ }^{* *}$ Significant at the 0.01 level. " Significant at the 0.05 level.

891 PM represents professional male drivers. PF represents professional female drivers.

892 NM represents non-professional male drivers. NF represents non-professional female drivers. 

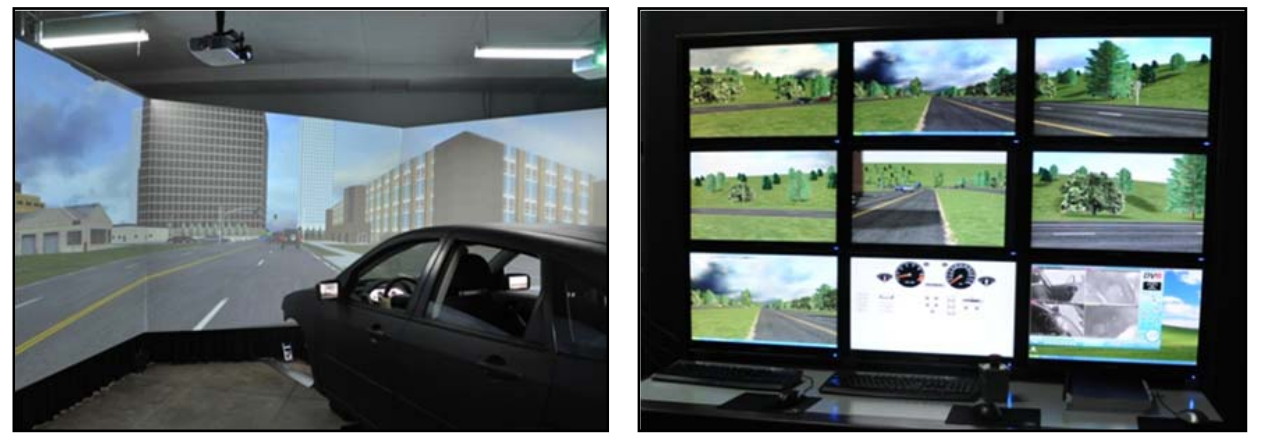

895

896

Figure 1: BJTU driving simulator cab

897 
898

899

900

901

902

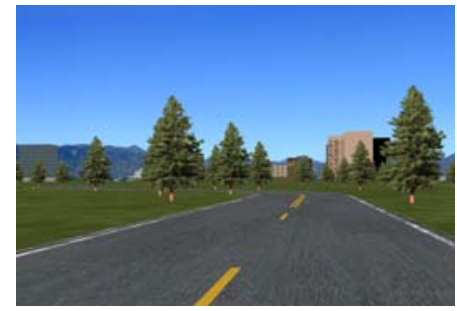

a. No fog

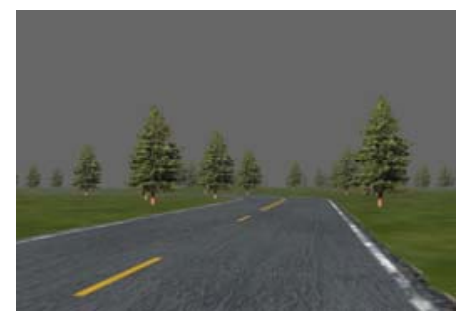

b. Light fog

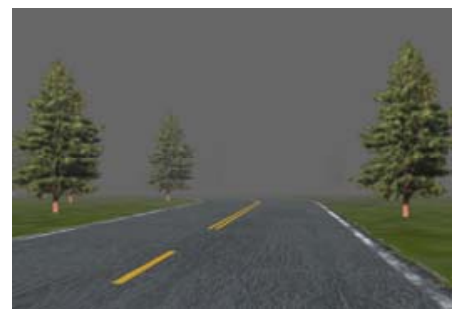

c. Heavy fog

Figure 2: The three fog conditions 

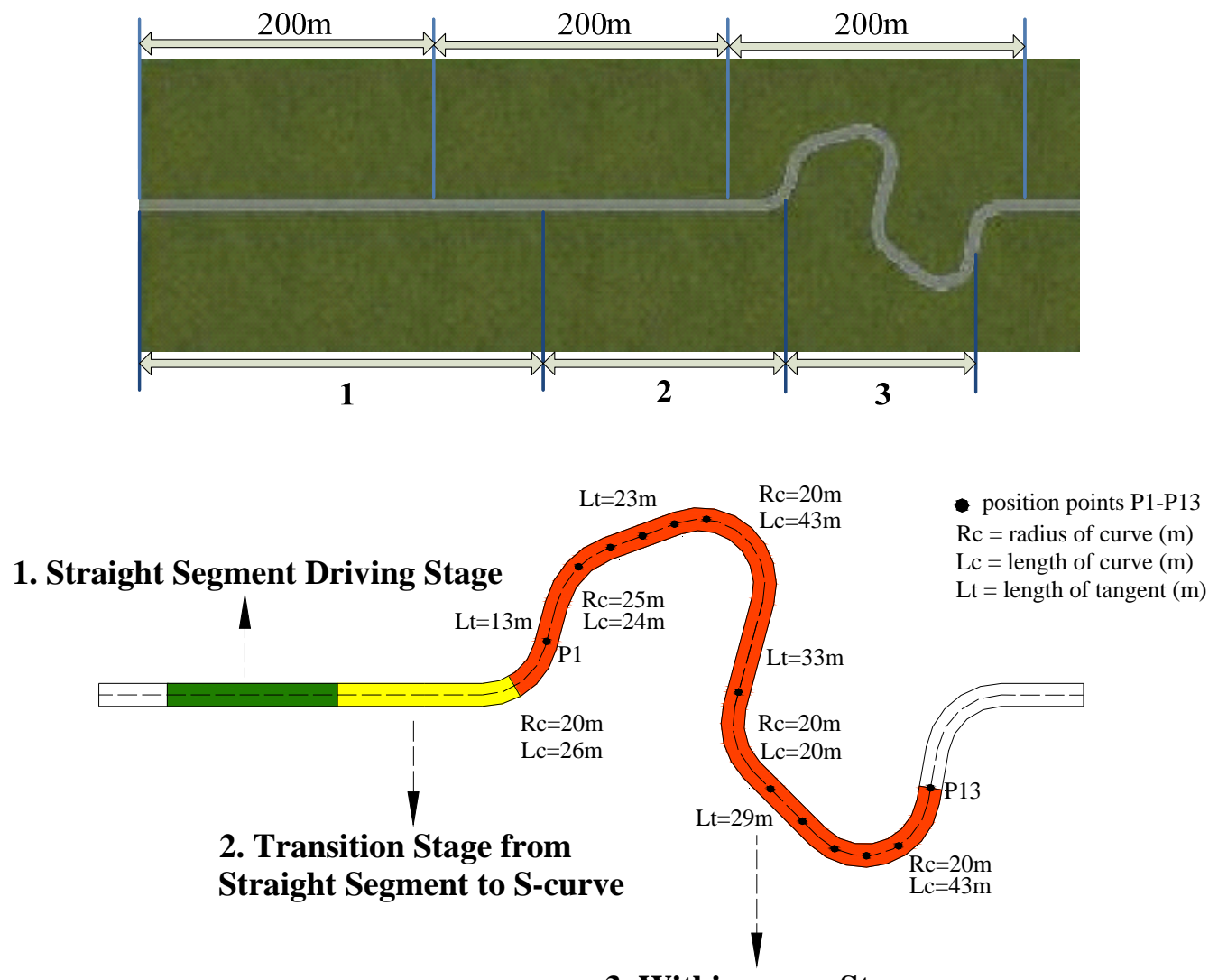

3. Within-curve Stage

905 Figure 3: Test road alignment and three stages of the curve negotiation process 

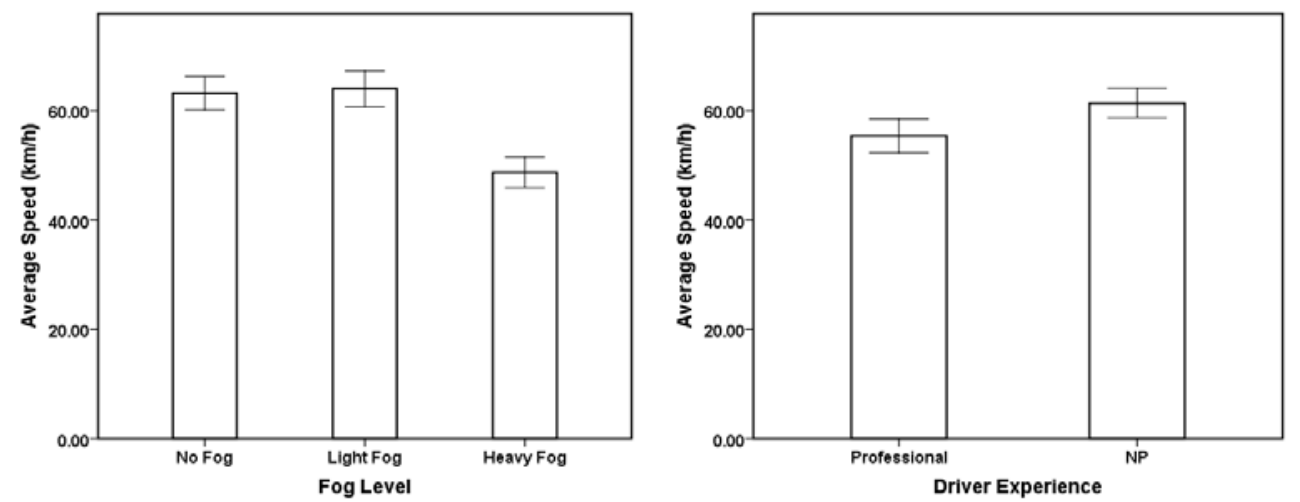

907

(a) Average speed in three fog conditions

(b) Average speed for different driver experience

909

910

Figure 4: Average speed on the straight segment

911 

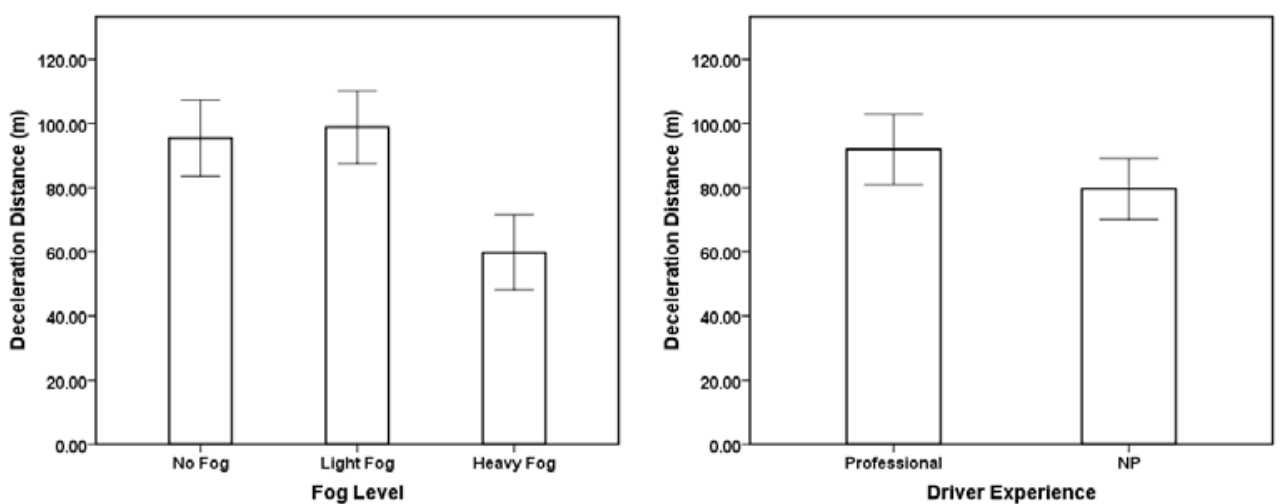

912

a. Deceleration distance in three fog conditions b. Deceleration distance for different driver experience

914

915 Figure 5: Deceleration distance in the transition stage from the straight segment to the 916 S-curve

917 


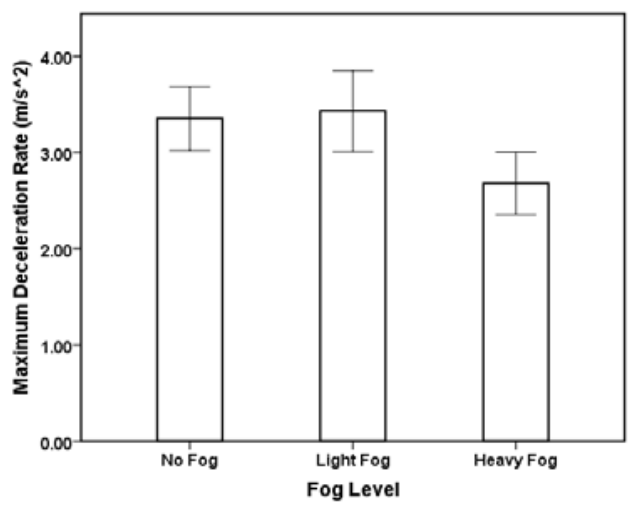

919

920

921

Figure 6: Maximum deceleration rate before the S-curve in three fog conditions 


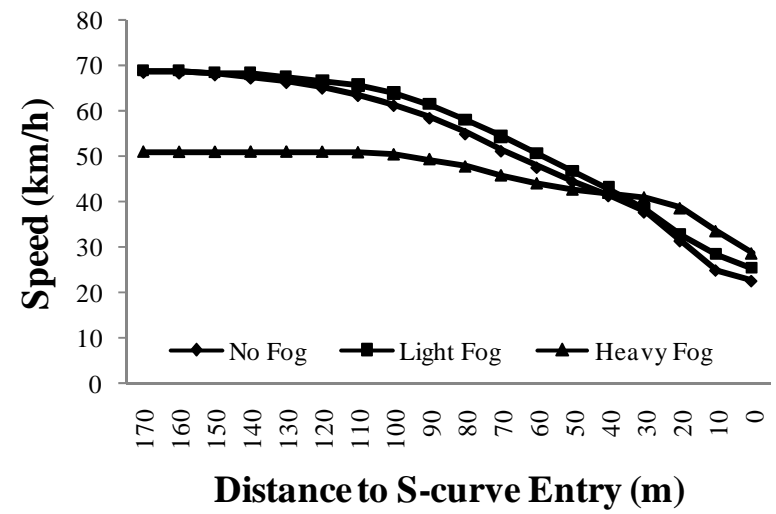

923

924

925

Figure 7: Average speed on the approach to the curve in the three fog conditions 


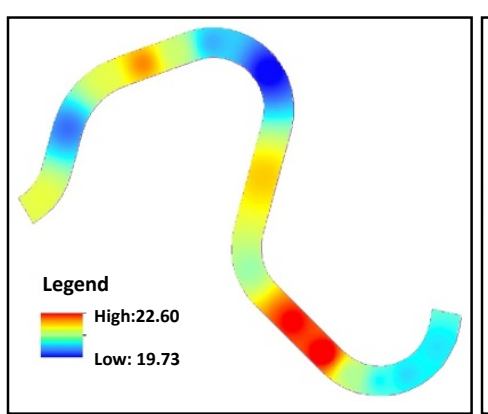

a. No Fog

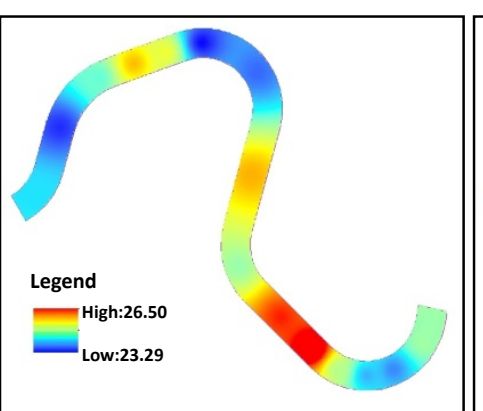

b. Light Fog

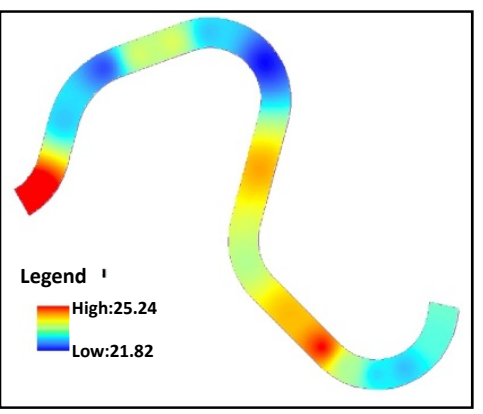

c. Heavy Fog

928

929

Figure 8: Speed changes in the three fog conditions

930 

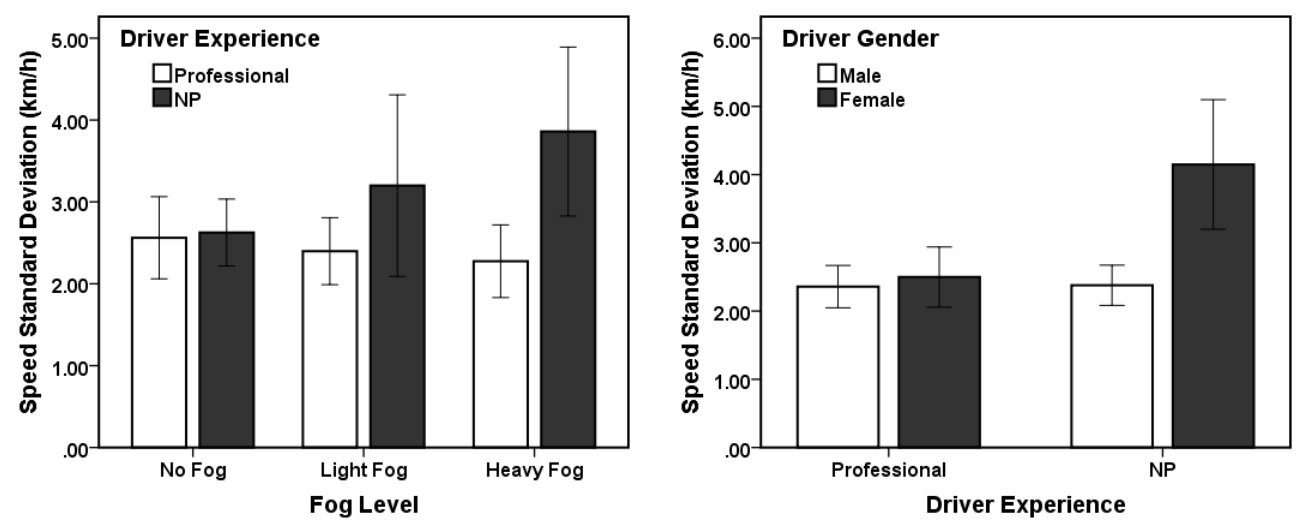

931

932

933

934

935

936 a. Speed S.D. for different fog conditions and driver experience experience and gender

Figure 9: Speed S.D. within the curve b. Speed S.D. for different driver 


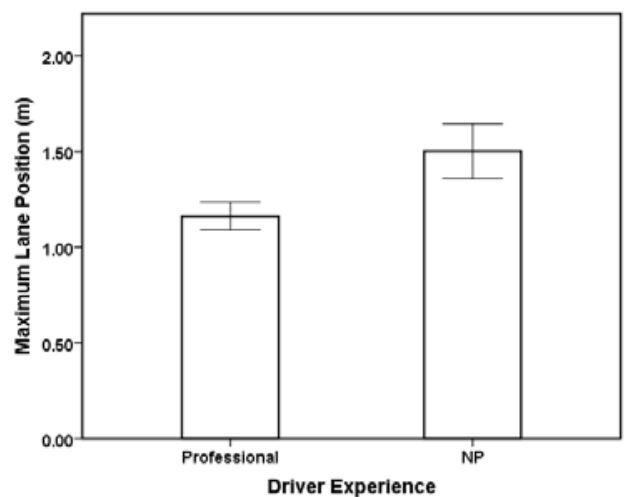

937

938

939

Figure 10: Maximum lane position within the curve for different driver experience 940 


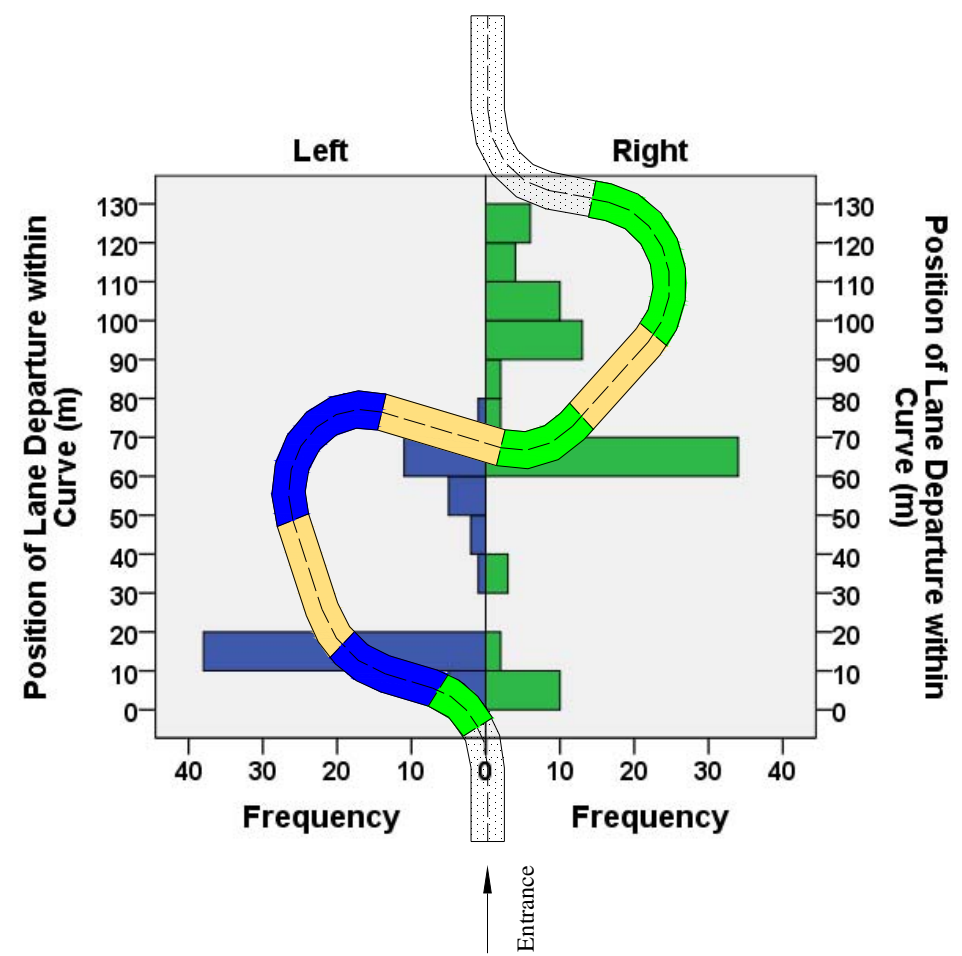

942

943 Figure 11: Frequency of drivers' maximum lane positions resulting in crossing lane boundaries at different locations within curve 

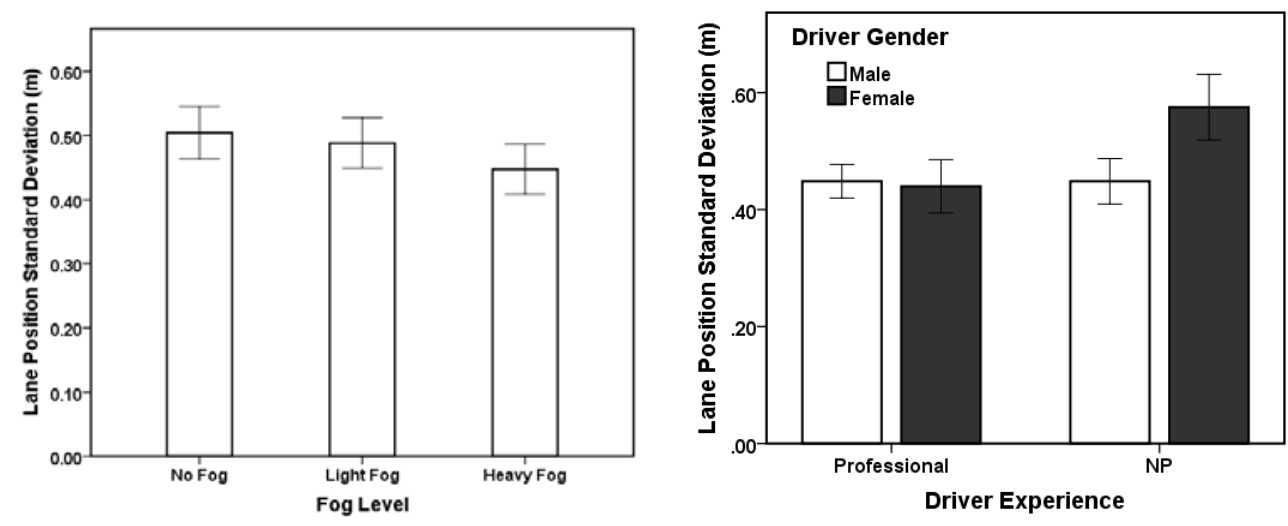

946

947

948

949

950

a. Lane position S.D. for different fog conditions

b. Lane position S.D. for different driver experience and gender

Figure 12: Lane position S.D. within the curve 